\title{
Inovar mobilizando os atores sociais e institucionais. A experiência de Salgueiro, Rio de Janeiro (RJ)
}

Flávio Alberto de Andrade Goulart, Daniel Trindade Araújo do Espírito Santo, Helena

Fernandes Ferraz, Victoria Mey Carmo Pereira

\section{RESUMO}

O artigo analisa o discurso dos atores na mobilização social e institucional na experiência de trabalho em Atenção Básica/Saúde da Família na UBS de Heitor Beltrão, Rio de Janeiro.

Revista da Rede APS 2020

Publicada em: 04/09/2020

Palavras-chave: Atenção Primária à Saúde; Acesso; Prêmio APS.

DOI:10.14295/aps.v2i3.149

Flávio Alberto de Andrade Goulart (Organização PanABSTRACT Americana de Saúde)

The article analyzes the discourse of the actors in social and institutional mobilization in the work experience in Primary Care / Family Health at the UBS of Heitor Beltrão, Rio de Janeiro.

Daniel Trindade Araújo do Espírito Santo (Universidade do Estado Keywords: Prmary Health Care; Access; PHC Prize. do Rio de Janeiro)

Helena Fernandes Ferraz, (Secretaria Municipal de Saúde do Rio de Janeiro)

Victoria Mey Carmo Pereira

(Secretaria Municipal do Rio de Janeiro)

Correspondência para:

Flávio Alberto de Andrade Goulart goulart.fa@gmail.com

Artigo premiado no concurso "Prêmio APS Forte para o SUS Acesso Universal" - selecionado por uma equipe de jurados especiais designados pela Organização Pan-Americana da Saúde no Brasil (OPAS) no Brasil. 


\section{VISÃO GERAL E CONTEXTO}

Bairro da Tijuca, Rio de Janeiro. Meio caminho entre a Zona Norte, mais pobre, e a Zona Sul da cidade, mais rica. Em ambas as regiões impera uma paisagem de morros, onde se situam as favelas, nas quais dominam o tráfico, a violência e a pobreza. Na Tijuca, a poucos metros da Praça Saenz Peña, logradouro símbolo do bairro, fica a Unidade de Saúde Heitor Beltrão, que atende a população do morro do Salgueiro, onde o trabalho ora analisado tem seu foco de ação.

O discurso dos atores da experiência situa o trabalho em Atenção Básica/Saúde da Família na cidade como atuante em duas modalidades distintas, identificadas como "no asfalto" e "no morro", com diferenças implícitas às duas situações. A UBS de Heitor Beltrão tem uma característica especial: fica no asfalto, mas atende também o morro. Mais precisamente, com sua cobertura de quase sete mil pessoas, tem uma quarta parte delas vivendo nas ladeiras e ruelas dos morros do Salgueiro e outros adjacentes, como o do Catrambi e do Borel.

\section{A EQUIPE}

A equipe é formada por gente jovem. A maioria na faixa dos trinta, no máximo, quarenta anos. Neste momento ela já não tem a mesma composição daquela que elaborou o trabalho aqui analisado. Alguns médicos, então residentes, completaram sua formação e foram para outros locais. Outros trabalhadores foram demitidos, vítimas das medidas de redução de investimentos em saúde, especialmente na atenção primária, tomadas pelas autoridades municipais.

Como consequência, a própria residência em Saúde da Família, ligada à Universidade do Estado do Rio de Janeiro (UERJ) teve, a partir do corrente ano, a unidade Heitor Beltrão excluída de seus campos de estágio.

Todavia, percebe-se que as pessoas sentem orgulho pelo reconhecimento proporcionado pelo Prémio APS Forte. Porém, nas palavras de daqueles que foram demitidos, mas que generosamente participaram do trabalho que permitiu as presentes observações, é possível captar a decepção pelo inesperado desfecho.
A liderança de uma das médicas aparece evidente, apesar de ser exercida com muita suavidade e discrição. Um outro médico, hoje afastado da equipe, parece também ter oferecido seu quinhão em tal quesito. Os depoimentos são unânimes em reconhecer em ambos um papel diferenciado, não só na concepção, mas também na operacionalização das ações. Isso se adiciona à atuação de pessoas da Escola do bairro, como será comentado adiante. Mas de toda forma o ambiente das relações interpessoais na equipe demonstrou-se extremamente solidário e afetivo, sendo os médicos tratados por seus prenomes, sem outro qualificativo (doutor, doutora) e até mesmo por apelidos carinhosos.

Deve ser mencionado, entretanto, que a equipe que atua em Heitor Beltrão não é formada apenas por pessoas ligadas à estratégia de Saúde da Família. Ao contrário, talvez a maioria seja de servidores de carreira da SMS, que ocupam parte dos postos burocráticos e mesmo de assistência. Entre estes, pelo que foi possível constatar, a ligação afetiva com o trabalho não parece ser tão exuberante. Se não há negação e hostilidade, pelo menos não parece haver afeto ou adesão evidentes. Foi diretamente mencionado em uma das entrevistas que a reação dos médicos especialistas lotados na Unidade é de resistência e mesmo de contestação à suposta competência dos médicos de família em tratar de situações tradicionalmente encaminhadas a eles, como condições de saúde da mulher ou da criança, por exemplo.

\section{O AMBIENTE}

A Unidade de Saúde Heitor Beltrão situa-se em prédio próprio, muito provavelmente erguido com tal finalidade. Com idade de algumas décadas, é bastante ampla, mas com funcionalidade sofrível, com seus corredores estreitos e mal iluminados. Apresenta estado de conservação precário, com paredes sujas, piso mal conservado e mobiliário arcaico e enferrujado. Tal situação agravou-se recentemente com o desabamento de uma parte do teto, o que obrigou a fechar toda uma ala, sobrecarregando o espaço remanescente. Nos momentos da visita, uma terça feira, período da tarde e quarta, manhã, era grande o 
movimento de pessoas, que formavam filas na porta e mesmo na área interna do prédio, com interações visivelmente inadequadas com os funcionários encarregados da recepção, dado o ruído e a falta de ventilação do ambiente. A Unidade possui regulares condições de acessibilidade, com rampas que conduzem aos seus espaços internos.

A Escola Bombeiro Geraldo Dias, pertencente à rede escolar municipal, fica situada em uma das entradas principais do morro do Salgueiro, aquela que dá acesso aos principais sítios do mesmo, por exemplo, a Escola de Samba e a região do Alto. Seu prédio de cor azul celeste, em estilo que originalmente seria neoclássico, bastante modificado por reformas sucessivas, se destaca na paisagem de construções precárias, pequenos sobrados sem pintura, biroscas de comércio, oficinas mecânicas e barracos. Ali dentro, muitas crianças brincando, com o alarido natural de sua condição infantil. Chama a atenção o portão fechado por grades de ferro e cadeados, sintoma do clima de violência da região. Vale ressaltar que equipe da Escola lamentou a suspensão das intervenções da Equipe de Saúde da Família de Heitor Beltrão, que consideravam altamente vantajosas para a escola.

\section{A MOTIVAÇÃO}

O foco principal do presente trabalho é representado pela preocupação da Equipe de Saúde da Família que atende a comunidade do Salgueiro ao observar um alto número de encaminhamentos de alunos da escola local por alterações de comportamento no ambiente escolar, a maioria antecipando diagnóstico de Transtorno do Déficit de Atenção/Hiperatividade (TDA/H), para o qual não havia condições de atendimento na Unidade-e nem mesmo no sistema de saúde da cidade como um todo. Surgiu assim, para eles, a necessidade de avaliar não só as crianças encaminhadas, mas também os contextos familiar e social em que estavam inseridas, no caso, em área de alta vulnerabilidade social

Este problema ultrapassa a visão biomédica e se destaca pela rapidez com que vem invadindo a vida cultural e social. Tais transtornos de atenção e hiperatividade, genericamente traduzidos como TDA/H, por muito tempo foram banalizados e desconsiderados. Hoje se sabe que eles são acometidos por uma disfunção cerebral, que precisa de diagnósticos formais e cujo tratamento é obrigatório. Tais quadros constituem o distúrbio mental mais comum na idade escolar e, por consequência, a principal causa de encaminhamento de crianças para serviços especializados, com seu cortejo de sintomas traduzidos por desatenção, hiperatividade e impulsividade. Consequência preocupante, embora não exclusiva do fenômeno, tem sido ampla prescrição de medicamentos como a Ritalina, sem maiores avaliações quanto à gravidade do quadro. Isso acabou se transformando em um problema de saúde pública, considerando, por exemplo, que nos EUA sua incidência vem crescendo de forma galopante, da mesma forma que no Brasil.

$\mathrm{Na}$ visão de um estudioso brasileiro (Lima, 2005), não caberia assumir um reducionismo sociocultural em substituição ao tradicional viés fisicalista, propondo uma aposta na possibilidade de diferentes discursos ou verdades sobre o problema e seus portadores, sem que ocorra a anulação de um pelo outro. Tal autor recomenda que se valorizem o contexto cultural e os atributos corporais e biológicos, configurando "bioidentidades", entre as quais o TDA/H seria apenas caso particular. Há que admitir, também, a existência de outras entidades psiquiátricas, como as fobias sociais, a anorexia, a bulimia, a síndrome do pânico e as drogadições, todas elas apresentando pontos de aproximação com a cultura e os modos de subjetivação contemporâneos. Assim, o quadro em foco pode ser visto como uma forma de bioidentidade, na qual se dá afinidade entre o perfil subjetivo do indivíduo e os comportamentos ou traços de personalidade ligados ao transtorno. Isso afastaria o TDA/H de uma noção de atenção como função cerebral mensurável objetivamente, ao contrário de se constituir como algo que depende de contextos culturais e arranjos coletivos. Enfim, a "atenção", tal qual é valorizada hoje, representa elemento inseparável da constituição dos sujeitos modernos, regulado que é pelas exigências da produção e pela expansão tecnológica. 
Assim, seria preciso pensar o problema fora de um molde reducionista, para enfim se entender e valorizar as exigências contemporâneas de exercício pleno da subjetividade, o que possibilitará maior riqueza e utilidade em termos de descrições e ações. Assim, a ênfase no corpo, na exterioridade e na atenção, ao contrário do que a cultura do TDA/H tenta provar, não significa necessariamente morte do campo dos valores e redução de tudo aos índices sensoriais da corporeidade.

A digressão acima, tendo como fonte autor reconhecido com fonte de conhecimento para a experiência, justifica e aclara o sentido das ações desenvolvidas na presente experiência, levada a efeito pela Equipe de Saúde da Família da Unidade Heitor Beltrão. Para uma descrição detalhada da experiência e para consultar os materiais, favor acesse o seguinte link:

https://apsredes.org/premioapsforte/osdesafios-da-implementacao-de-acoes-empromocao-de-saude-no-cenario-escolar-relatode-experiencia-de-um-grupo-de-criancas-nosalgueiro/

\section{DISCUSSÃO}

\section{FATORES FAVORECEDORES}

Esta experiência foi construída em bases sólidas de afeto e sintonia dentro de uma equipe. Foram abundantes as observações relativas aos fatores favorecedores, sem impedimento de que também aspectos negativos tivessem sido lembrados, como se verá a seguir.

A primeira evocação diante da questão acima, trazida pelos participantes do grupo focal, foi do sentimento de vontade, desejo e mesmo alegria em participar do trabalho. Isso se viu correspondido, destacadamente, pela percepção de correspondência entre as ações desenvolvidas e a expectativa e as necessidades da população do morro e da própria equipe da escola. Isso permitiu com que houvesse adesão e simpatia ao trabalho realizado, tanto interna como externamente, sendo considerados fatores importantes no sucesso.
Sem dúvida, a busca de parcerias e de articulações foi dada como acertada e bemsucedida, devendo ser destacado que isso se deu dentro de um panorama absolutamente eclético, envolvendo instituições tão diversas como órgãos oficiais (CAPS, CRAS, Conselho Tutelar) ao lado de comércio local e escola de samba, dentro de um enfoque de ampla intersetorialidade. Uma das professoras da escola ouvida durante o trabalho de análise local foi feliz em falar do processo de aproximação entre as equipes de saúde e escolar: "ninguém baixou aqui de paraquedas". O resultado mais palpável é de que foram geradas relações recíprocas de confiança.

De forma sintonizada a isso, houve muita ênfase, particularmente por parte dos médicos e professores, a respeito de um foco no trabalho "em rede". Curiosamente, isso era também um mantra difundido pelo órgão gestor municipal de saúde, que inclusive criou um coordenação ad-hoc com tal tema. Na prática, todavia, quando a equipe local tentou discutir o assunto junto à direção regional da SMS, para ampliá-lo e instrumentalizá-lo, receberam, segundo eles, apenas respostas consideradas burocráticas e protelatórias, traduzida por eles como "pacotes" centrais a que caberia apenas "desembrulhar". De toda forma, vale ressaltar um certo efeito de "catálise" nessas práticas, que fez com que algumas parcerias abrissem caminho para outras, que nem haviam sido cogitadas.

Liderança foi um aspecto fundamental, embora trazida à cena de forma muito discreta. Neste campo, foi lembrado (e se tornou perceptível também) o importante papel da médica de Saúde da Família e da diretora da Escola.

Pode-se dizer também que foi um trabalho que teve, durante toda sua direção, um foco bem definido, que era a situação preocupante do mau desempenho escolar das crianças atendidas, associado a práticas indesejáveis de medicalização. A expressão de um dos participantes (ACS) do grupo focal traduziu isso à perfeição: "era preciso ir além das prescrições". Para isso, é claro, houve necessidade de dobrar esforços para manter a continuidade, além de resiliência, pois em uma 
primeira aproximação as dificuldades em abordar o tema pareceram insuperáveis.

A expressão "trabalho em rede", referida acima, na verdade corresponde a uma dinâmica que já era assumida pela equipe de Saúde da Família desde a sua introdução no cenário de sua área de abrangência. Com efeito, eles se fizeram presentes em uma série de grupos temáticos já existentes no território, como por exemplo, Paz \& Filhos (que na prosódia carioca soa como "pais e filhos"), de mulheres artesãs, de famílias desestruturadas, de familiares de presidiários, além de outros.

O próprio trabalho na escola sem dúvida deriva de tal direcionamento "em rede". Expressão significativa, utilizada por um dos participantes do grupo focal, traduz de forma quase poética a atuação no mundo escolar: "aquelas crianças eram invisíveis; era preciso que elas se tornassem visíveis".

Como seria de se esperar, a abordagem familiar peculiar à estratégia de Saúde da Família e a realização de visitas domiciliares foram também considerados fatores diferenciais positivos, lamentavelmente comprometidos pelo recuo da atenção básica na cidade do Rio que ocorreu durante os anos de 2018 e 2019.

De forma associada a tais fatores positivos, são apontados alguns determinantes que favoreceram também a sustentabilidade da experiência, tais como: a impressão generalizada, embora não confirmada quantitativamente, que a atuação na saúde escolar contribuiu para minorar o problema da medicalização e mesmo da sociabilidade das crianças; a geração de sensibilidade comunitária a tal problema, confirmada pela "catálise" que as parcerias possibilitaram; o sentimento gratificante e de atuação positiva por parte da equipe de Saúde da Família, face ao enfrentamento de um problema grave, particularmente por terem auferido o prêmio APS Forte.

Digno de menção, ainda, é o fato de que a visita aos serviços de saúde de Granada, Espanha, em fevereiro de 2020, como resultado da premiação a eles conferida, deu aos visitantes a impressão de que realmente estiveram "fazendo a coisa certa" ao longo de sua atuação no Morro do Salgueiro.

\section{DIFICULDADES E OBSTÁCULOS}

O problema principal foi, sem dúvida, o processo de deterioração do sistema de saúde do Rio, iniciado na atenção básica, no âmbito de uma cidade em alta vulnerabilidade econômica e social. Isso foi algo muito sério, sem dúvida, pois de acordo ao indicado pela equipe, passou-se de uma área de cobertura de 2,8 mil pessoas para 5,8 mil, ao mesmo tempo em que os agentes comunitários de saúde foram reduzidos de seis para quatro. Além disso, os ACS tiveram que realizar parte de sua jornada de trabalho dentro da própria Unidade de Saúde da Família, acumulando agora as funções de recepcionistas, dada a demissão de outros funcionários que tinham tal encargo.

Sem dúvida, também, a complexidade dos processos de trabalho da estratégia de Saúde da Família pode ter funcionado como mais um dos obstáculos ao total êxito da experiência. O trabalho multidisciplinar, a atuação de generalistas, a realização sistemática de visitas domiciliares, o acompanhamento de indicadores, a vigilância territorial, são tarefas desafiadoras, que precisam de muita dedicação e recursos.

\section{LIÇÕES APRENDIDAS}

O primeiro tópico a destacar é representado pela liderança e a boa condução com que a experiência do Salgueiro pôde contar. Entre os atributos associados a isso estão a capacidade de tomada de decisões, o carisma, o espírito empreendedor, além de marcante embasamento teórico e mesmo ideológico, além de qualificação técnica dos participantes.

Isso, entretanto, teria pouco a oferecer se não houvesse, na retaguarda de pessoas consequentes, responsáveis e dotadas de forte adesão ao projeto, sejam médicos, ACS, técnicos ou outros profissionais, aspectos que podem ser traduzidos também por qualificação de conhecimentos, tradição de discussões em saúde, capacidade empreendedora, militância, além de aceitação da liderança e inserção em entidades participativas. 
Registramos o efetivo desenvolvimento de boas práticas sociais locais, com busca de equilíbrio e sintonia entre as propostas de participação originadas da equipe e as da sociedade, com a produção de efeitos concretos. A escolha da intervenção foi apropriada e capaz de unir o desejo, a vontade e o afeto da equipe de saúde com uma necessidade real da comunidade de usuários. Pode-se falar, assim, de um substrato conceitual que envolve noções de cidadania, direitos coletivos e responsabilidade pública.

A boa articulação externa foi sem dúvida um ingrediente importante na experiência do Salgueiro. Não há dúvida que seus a(u)tores souberam buscar e encontraram interlocutores seletos individuais ou institucionais, que foram capazes de oferecer respaldo técnico e cobertura política ao desenvolvimento do seu projeto, como aconteceu na relação com o CARIN (CADE Infantil), CRAS, Conselho Tutelar, comércio local e outras instâncias.

Esta experiência traz muitos elementos inovadores, seja do ponto de vista gerencial ou assistencial, fugindo da moldura institucional tradicional, como foi o caso da busca de parceiros para a realização do projeto e da própria valorização de um tema por assim dizer "órfão" nos serviços de saúde e nas escolas. Aqui se diferenciou a inovação, incontestável, da mera novidade, tendo como diretriz norteadora a ousadia e o destemor frente às possibilidades de erro, de reversão, além dos riscos de se buscar o desconhecido. E, particularmente, a preocupação em tentar criar uma situação que pudesse ser sustentável e replicada para outras realidades.

O fato de ter sido experiência premiada em nível nacional mostra outra lição importante, constituída pela busca de articulação e da difusão de uma ocorrência local entre interlocutores externos, configurando a preocupação com uma verdadeira pedagogia do exemplo, fundamental no processo de construção de políticas e práticas públicas.

A busca de sustentabilidade das práticas desenvolvidas, não só em termos financeiros, de estrutura e processos, mas também nos planos cultural, simbólico e político, também é aspecto fundamental.
Entretanto, os percalços enfrentados pelo setor de saúde na cidade do Rio constituíram forte obstáculo a que isso acontecesse de fato.

Em suma, torna-se preciso pensar, sempre, como "proteger" práticas inovadoras desta natureza. Torna-se necessário o enraizamento destas experiências no imaginário da comunidade e dos gestores, para que e os conhecimentos que elas acarretam não pereçam.

\section{LEITURAS CORRELATAS}

\section{SOBRE TRANSTORNOS DE APRENDIZADO E CONDIÇÕES SEMELHANTES}

- Rossano Cabral Lima. Somos todos desatentos? O TDH/A e a construção das bioidentidades. Relume dumará. Rio de Janeiro. 2005

- Luciana Vieira Caliman. A biologia moral da atenção: a constituição do sujeito (des)atento, Rio de Janeiro; s.n; 2006. 174 p. ilus. Acessível em: http://bases.bireme.br/cgibin/wxislind.exe/iah/online/?IsisScript $=i a h / i a h . x i s \& s r c=$ google $\&$ base=LILACS \&lang=p\&nextAction=Ink\&exprSearch $=443496 \&$ indexSearch $=$ ID

\section{SOBRE TRABALHO EM REDE}

- Elaine Cristina da Silva Gazignato, Carlos Roberto de Castro e Silva. Saúde mental na atenção básica: o trabalho em rede e o matriciamento em saúde mental na Estratégia de Saúde da Família. Saúde Debate. Rio de Janeiro, v. 38, n. 101, p. 296-304, abr-jun 2014.

\section{SOBRE A POLÍTICA DE ATENÇÃO BÁSICA NO} BRASIL

- Márcia Valéria Guimarães Cardoso Morosini, Angélica Ferreira Fonseca. Revisão da Política Nacional de Atenção Básica numa hora dessas? Cad. Saúde Pública 33 (1)13 Fev 2017. Acessível em 


\section{https://doi.org/10.1590/0102- 311X00206316}

- Política Nacional de Atenção Básica. Acessível em: http://bvsms.saude.gov.br/bvs/saudel egis/gm/2017/prt2436 $22092017 . h$ $\underline{\mathrm{tml}}$

\section{SOBRE A CULTURA ORGANIZACIONAL}

- MORGAN, G., 1986. Imagens da organização. São Paulo: Atlas. Acessível em:

http://www.gbic.com.br/ibes2k9si/1\% BA\%20Semestre/livros/Projeto\%20Livr o\%20Adm\%20lmagens\%20da\%200rga nizao.pdf

\section{SOBRE INOVAÇÃO}

- Inovação na APS forte. Acessível em https://apsredes.org/inovacao-na-apsforte/

- Laís Silveira Costa. Inovação nos serviços de saúde: apontamentos sobre os limites do conhecimento. Cad. Saúde Pública, Rio de Janeiro, 32 Sup 2, 2016. Acessível em http://www.scielo.br/pdf/csp/v32s2/p t 1678-4464-csp-32-s2-e00151915.pdf

\section{SOBRE A EXPERIÊNCIA}

- https://apsredes.org/premioapsforte/ os-desafios-da-implementacao-deacoes-em-promocao-de-saude-nocenario-escolar-relato-de-experienciade-um-grupo-de-criancas-nosalgueiro/

\section{ADENDO}

As presentes observações analíticas são os resultados da análise da documentação proporcionada pela equipe participante, combinadas pelas informações coletadas em uma visita de campo, realizada pelo Consultor Flavio Goulart, entre 11 e 12 de março de 2020. As interações ocorreram através de um grupo focal, algumas entrevistas individuais, além de visitas aos locais de prática. $O$ grupo focal teve a duração de duas horas e dele participaram membros da equipe de Saúde da Família local, sendo dois médicos, dois agentes comunitários de saúde, uma técnica de enfermagem, uma residente, uma psicóloga e uma estudante de medicina estagiária. Foram entrevistados individualmente uma médica de SF, uma psicóloga que participou diretamente dos trabalhos, além de duas professoras em função de gestão na Escola do bairro. 